\title{
MOX Sensors to Ensure Suitable Parameters of Grated Parmigiano Reggiano Cheese ${ }^{\dagger}$
}

\author{
Marco Abbatangelo *, Giorgio Duina, Elisabetta Comini and Giorgio Sberveglieri \\ Department of Information Engineering, University of Brescia, via Branze, 38, 25123 Brescia, BS, Italy; \\ giorgio.duina@unibs.it (G.D.); elisabetta.comini@unibs.it (E.C.); giorgio.sberveglieri@unibs.it (G.S.) \\ * Correspondence: m.abbatangelo@unibs.it \\ + Presented at the 8th GOSPEL Workshop. Gas Sensors Based on Semiconducting Metal Oxides: Basic \\ Understanding \& Application Fields, Ferrara, Italy, 20-21 June 2019.
}

Published: 19 June 2019

Parmigiano Reggiano (PR) cheese is a long-ripened hard cheese made in Northern Italy registered as a Protected Designation of Origin (PDO) in the European Union. PR is a well- known product for its high content of nutrients and taste. It is present on the market essentially in two formats: trimmed pieces and grated cheeses. When faced with a shortfall of demand of trimmed methods, sales of grated PR have increased by 5.2\% [1]. Grated cheese must account specific technical parameters, as established in the procedural guideline [2]. They are inter alia: minimum 12 months of ripening, less than $25 \%$ of particles having diameter less than $0.5 \mathrm{~mm}$, and a quantity of rind less than $18 \%(\mathrm{w} / \mathrm{w})$. However, it can happen that this limit can be exceeded because of process issues (e.g., mixing errors) or fraudulent reasons. This, together with the increase in sales, is the main reason why our attention focused on this kind of product.

In this work, grated PR samples were analyzed by a sensors system with 8 MOX gas sensors inside. Six of them were produced at Sensor Laboratory (University of Brescia, Italy). Three of them were nanowires of MOX (two were tin oxides nanowires sensors using a gold catalyst on the alumina substrate and functionalizing one of them with gold clusters; the third sensor had an active layer of copper oxide nanowires). The other three sensors are prepared with Rheotaxial Growth and Thermal Oxidation (RGTO) thin film technology (one tin oxide functionalized with gold clusters, two pure tin oxide). The last two are commercial MOX sensors produced by Figaro Engineering Inc. (TGS2611 and TGS2602). Headspace of different types of grated PR cheese were analyzed, totalling 452 samples; all of them were provided by Consorzio del Formaggio Parmigiano Reggiano (CFPR). Three characteristic parameters were taken into account: ripening degree (12 months or 24 months), rind working process (i.e., brushed or washed) and rind percentage (lower than 18\%, between $18 \%$ and $26 \%$, higher than $26 \%$ ). Sensors' resistances were recorded and their maximum variations for each measure were extracted as features. Data were analyzed using artificial neural networks (ANNs) as classifiers. Given the complexity of the problem due to the different considered variables of the grated PR, a hierarchical approach has been used [3]. The problem was divided in three steps: recognition of ripening degree; then, distinction of rind working process; finally, identification of rind percentage. For each step, a different number of ANNs was used: at the beginning, one ANN sorted samples in 12 months or 24 months classes; in the second step, two ANNs (one for each of the two classes of the previous step) classify the rind working process; at the end, four networks recognize rind percentage in three classes: lower than $18 \%$, between $18 \%$ and $26 \%$ and higher than $26 \%$. ANNs were trained until they reached the higher classification rate. Results are shown in Table 1. Sensors' array is able to recognize correctly all the samples in 5 out of 7 tasks. However, most misclassified samples are those with 12 months ripening and washed rind and this could be caused by higher quantity of humidity that characterizes these samples. 
Table 1. Classification rates of ANNs for each step.

\begin{tabular}{|c|c|c|c|c|c|}
\hline STEP 1 & & \multicolumn{2}{|c|}{ STEP 2} & \multicolumn{2}{|c|}{ STEP 3} \\
\hline \multirow{4}{*}{$\begin{array}{c}\text { Ripening } \\
\text { (12 months vs. } 24 \\
\text { months) }\end{array}$} & \multirow{4}{*}{$98.89 \%$} & \multirow{2}{*}{$\begin{array}{c}\text { Rind working } \\
\text { process for } 12 \\
\text { months } \\
\text { Samples } \\
\text { (Washed vs. } \\
\text { Brushed) }\end{array}$} & \multirow{2}{*}{$100 \%$} & $\begin{array}{l}\text { Rind percentage } \\
\text { (12 months } \\
\text { washed) }\end{array}$ & $73.33 \%$ \\
\hline & & & & $\begin{array}{l}\text { Rind percentage } \\
\text { (12 months } \\
\text { brushed) }\end{array}$ & $100 \%$ \\
\hline & & $\begin{array}{l}\text { Rind working } \\
\text { process for } 24 \\
\text { months }\end{array}$ & $100 \%$ & $\begin{array}{l}\text { Rind percentage } \\
\text { (24 months } \\
\text { washed) }\end{array}$ & $100 \%$ \\
\hline & & $\begin{array}{c}\text { samples } \\
\text { (Washed vs. } \\
\text { Brushed) }\end{array}$ & $100 \%$ & $\begin{array}{l}\text { Rind percentage } \\
\text { (24 months } \\
\text { brushed) }\end{array}$ & $100 \%$ \\
\hline
\end{tabular}

\section{References}

1. Available online: https://www.parmigianoreggiano.it/comunicazione/rapporto_annuale_dell_attivita/ default.aspx (accessed on 27 May 2019).

2. D.P.C.M. (Decree of the President of the Council). Estensione Della Denominazione di Origine del Formaggio «Parmigiano Reggiano»alla Tipologia «Grattugiato»; Gazzetta Ufficiale: Italy, 1991; Volume 83.

3. Abbatangelo, M.; Núñez Carmona, E.; Sberveglieri, V.; Zappa, D.; Comini, E.; Sberveglieri, G. Application of a novel S3 nanowire gas sensor device in parallel with GC-MS for the identification of rind percentage of grated Parmigiano Reggiano. Sensors 2018, 18, 1617. doi:10.3390/s18051617.

(C) 2019 by the authors. Licensee MDPI, Basel, Switzerland. This article is an open access article distributed under the terms and conditions of the Creative Commons Attribution (CC BY) license (http://creativecommons.org/licenses/by/4.0/). 